\title{
INTEGRASI DATA RESISTIVITAS 2D DENGAN PARAMETER FISIS DAN MEKANIS TANAH UNTUK EVALUASI DAYA DUKU TANAH (STUDI KASUS: RUAS JALAN KAWASAN JIIPE, MANYAR, GRESIK)
}

\author{
Billy Dovan Yuspancana, Widya Utama, Moh. Singgih Purwanto, Ayi Syaeful Bahri \\ Departemen Teknik Geofisika, Fakultas Teknik Sipil Lingkungan dan Kebumian, Institut Teknologi Sepuluh Nopember, \\ Surabaya \\ e-mail: billydovan97@gmail.com
}

\begin{abstract}
Abstrak. Kawasan Industri JIIPE terletak di Kecamatan Manyar, Kabupaten Gresik yang geologi lapisan dangkalnya didominasi oleh lempung yang merupakan tanah lunak. Tanah lempung memiliki sifat plastis dan kuat geser yang rendah, kondisi tersebut akan menimbulkan deformasi yang besar pada lempung bila pembebanan melebihi kapasitas daya dukungnya. Penelitian ini dilakukan untuk mengetahui nilai daya dukung tanah kondisi lapangan melalui integrasi data geofisika dengan parameter sifat fisis dan mekanis tanah. Data geofisika didapatkan dari pengukuran metode geolistrik dengan hasil data berupa penampang resistivitas 2D. Konfigurasi Wenner-Schlumberger diterapkan pada pengambilan data geolistrik dengan tujuan mendapatkan resolusi vertikal dan horizontal yang baik. Penampang resistivitas mempunyai peranan sebagai dasar dalam penentuan batas lapisan tanah serta ketebalan material timbunan. Dari penampang resistivitas yang didapat, dilakukan pengelompokkan nilai resistivitas berdasarkan jenis tanah di lokasi penelitian dengan bantuan data pembanding meliputi data kadar air dan data borelog. Nilai resistivitas kecil pada penampang didefinisikan sebagai tanah lempung dengan rentang nilai $0.1 \Omega \mathrm{m}-5.5 \Omega \mathrm{m}$, diikuti dengan rentang resistivitas 5.5-6.4 $\Omega \mathrm{m}$ didefinisikan sebagai pasir, dan 6.4$170 \Omega \mathrm{m}$ sebagai material timbunan karbonat. Hasil dari integrasi data resistivitas 2D dengan parameter fisis dan mekanis didapatkan nilai daya dukung tanah pada lintasan 3, 4, 5, dan 6 pengukuran geolistrik beruturut-turut senilai $54.5 \mathrm{kN} / \mathrm{m}^{2}, 58.4 \mathrm{kN} / \mathrm{m}^{2}, 56.2 \mathrm{kN} / \mathrm{m}^{2}$, dan $51.7 \mathrm{kN} / \mathrm{m}^{2}$.
\end{abstract}

Kata Kunci: daya dukung tanah; parameter fisis dan mekanis; resistivitas

\begin{abstract}
JIIPE Industrial Estate is located in Manyar District, Gresik Regency. The geology of the shallow layer is dominated by clay which include to the type soft soil. Clay has low bearing capacity and plastic property that will cause large deformations on the ground if the load exceeds its bearing capacity. This research was conducted to determine the value of soil bearing capacity on existing conditions based on integration of geophysical field with physical and mechanical properties of soil parameters. Geophysical data obtained from the measurement of geoelectric methods with the results of data in the form of $2 D$ resistivity cross sections. Wenner-Schlumberger configuration is applied to geoelectric data acquisition with the aim of obtaining good vertical and horizontal resolution. The resistivity section has a role as a basis for determining soil boundaries and the thickness of embankment material. From the resistivity cross section, grouping the resistivity values based on the type of soil at the research location was carried out with the help of comparative data including water content data and borelog data. The small resistivity value in the cross section is defined as clay with a value range of $0.1 \Omega \mathrm{m}-5.5 \Omega \mathrm{m}$, followed by a resistivity

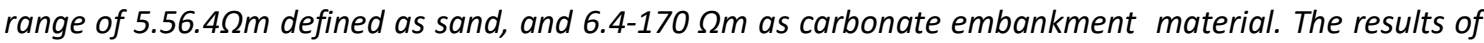
the integration of $2 D$ resistivity data with physical and mechanical parameters obtained values of soil bearing capacity on 3, 4, 5, and 6 line of geoelectric measurements of $54.5 \mathrm{kN} / \mathrm{m}^{2}, 58.4 \mathrm{kN} / \mathrm{m}^{2}, 56.2$ $\mathrm{kN} / \mathrm{m}^{2}$ respectively.
\end{abstract}

Keywords: bearing capacity; physical and mechanical parameters; resistivity

\section{PENDAHULUAN}

Menurut Departemen Pekerjaan Umum (2005) tanah lunak adalah tanah yang memiliki kuat geser kurang dari $40 \mathrm{kPa}$ dengan kompresibilitas yang tinggi. Permasalahan tanah lunak ini juga terdapat pada wilayah penelitian yang terletak di Kecamatan
Manyar, Gresik dengan geologi lapisan dangkal pada wilayah ini didominasi oleh lempung (J. Supandjono dkk., 1992). Penimbunan pada tanah lempung untuk konstruksi jalan dapat mengalami kegagalan karena daya dukung dari lempung sendiri yang tidak mampu menerima beban dari material 
timbunan. Kegagalan penimbunan yang dimaksud seperti terjadinya deformasi drastis yang diindikasikan dengan adanya amblesan - amblesan di permukaan seperti kasus yang terdapat pada lokasi penelitian yaitu ruas jalan kawasan industri Java Integrated Industrial and Port Estate (JIIPE).

Permasalahan ini dapat diidentifikasi dari bidang geofisika dengan mengetahui sejauh mana deformasi yang telah terjadi pada tanah lunak di bawah material timbunan, salah satunya dengan menggunakan metode geolistrik. Metode Geolistrik tahanan jenis yang memanfaatkan perbedaan nilai potensial dari injeksi kuat arus mampu memberikan gambaran yang baik terkait bawah permukaan melalui penampang sebaran nilai resistivitas yang dihasilkan (Lida Maulida, 2013). Proses perhitungan untuk mengetahui nilai daya dukung optimum tanah dari wilayah penelitian dapat dilakukan dengan memasukkan nilai parameter fisis dan mekanis tanah kedalam geometri bawah permukaan yang didapatkan dari penampang resistivitas.

\section{TINJAUAN PUSTAKA}

\section{Geologi Daerah Pengukuran}

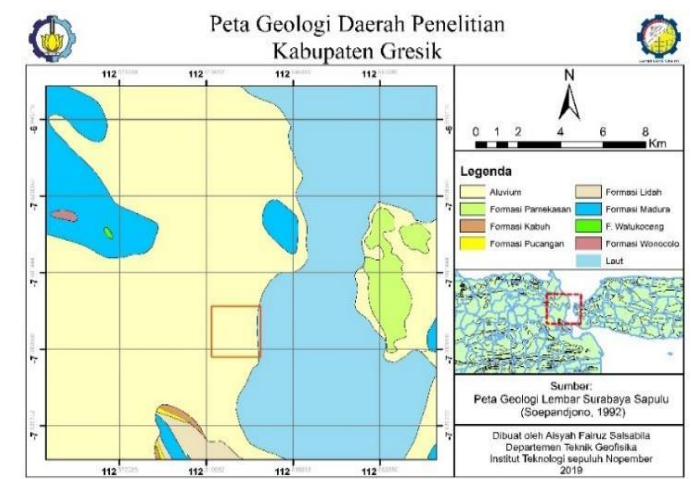

Gambar 1. Peta Geologi Regional Wilayah Penelitian

Area penelitian Kawasan Industri JIIPE terletak pada Wilayah Kecamatan Manyar, Kabupaten Gresik dengan kondisi geologi tersusun oleh endapan alluvium (Qa) yang secara langsung berhadapan dengan Pulau Madura di bagian Timur. Sesuai dengan gambar (2.1) lokasi penelitian didominasi oleh lempung. Endapan aluvium ini terbentuk pada masa Holosen yang berbatasan langsung dengan Laut Selat Madura. Endapan sedimen sepanjang Selat Madura dibentuk oleh endapan pantai yang masuk ke daratan sampai \pm 5 km. Berdasarkan Peta Geologi Lembar Surabaya dan Sapulu (J. Supandjono dkk., 1992) endapan alluvium di daerah penelitian terdiri atas kerikil, pasir, lempung, dan pecahan cangkang fosil di beberapa tempat.

\section{Metode Resistivity}

Tujuan dari survei geolistrik adalah untuk menentukan distribusi resistivitas bawah permukaan dengan melakukan pengukuran pada permukaan tanah. Pengukuran metode resistivitas dilakukan dengan menginjeksikan arus ke tanah melalui dua elektroda arus (C1 dan C2), dan mengukur perbedaan tegangan yang dihasilkan pada dua elektroda potensial (P1 dan P2).

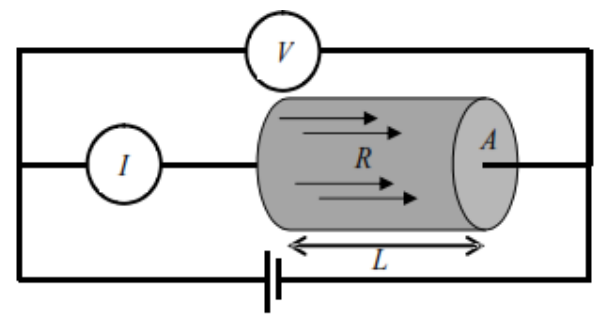

Gambar 2. Aliran arus pada benda silinder (W. M. Telford, 1990)

Penerapan secara sederhana tampak pada Gambar 2 yaitu terhadap benda silinder yang memiliki hambatan jenis $(\rho)$, arus listrik (I), maka akan berbanding lurus dengan luas penampang $(A)$ dan beda potensial antara ujung-ujungnya $(\Delta \mathrm{V})$, namun berbanding terbalik dengan panjangnya (L).

$$
\rho=\frac{V A}{I L}
$$

Konfigurasi Wenner-Schlumberger memiliki pemetaan distribusi nilai resistivitas yang cukup baik secara horizontal maupun vertikal bila dibandingkan dengan konfigurasi yang lain (Arsyadi, 2017; Winarti, 2013). Nilai K untuk konfigurasi Wenner-Schlumberger sebagai berikut:

$$
K=\pi n(n+1) a
$$

\section{Metode Inverse Distance Weighting}

Inverse Distance Weighting (IDW) merupakan teknik interpolasi yang memperhitungkan adanya hubungan letak ruang atau jarak, dan merupakan kombinasi linier atau harga rata-rata terbobot dari titik data yang ada disekitarnya. Tujuan dari penggunaan fungsi inverse distance sebagai estimator adalah memberikan bobot lebih pada sampel tedekat, maka hanya dipertimbangkan nilai bulat dari parameter terdekat. Metode IDW umumnya terselesaikan dengan persamaan berikut.

$$
\lambda_{i}=\frac{d_{i 0}^{-p}}{\sum_{i=1}^{n} d_{i 0}^{-p}}
$$


$\mathrm{d}_{\mathrm{io}} \quad=$ jarak antar titik pengamatan ke-I dengan titik yang diduga

$\mathrm{p}=$ power (bilangan bulat)

\section{Daya Dukung Tanah}

(Pramono, 2008)

Kapasitas/daya dukung tanah (bearing capacity) adalah kekuatan tanah untuk menahan suatu beban yang bekerja padanya yang biasanya disalurkan melalui pondasi. Kapasitas/daya dukung ultimit (ultimate bearing capacity) ( $q_{u}$ ) didefinisikan sebagai beban maksimum persatuan luas saat tanah masih dapat mendukung beban dengan tanpa mengalami keruntuhan. Bila diturunkan kedalam fungsi matematis yaitu sebagai berikut:

$$
q u=\frac{P u}{A}
$$

Dengan qu adalah kapasitas dukung batas $\left(\mathrm{kN} / \mathrm{m}^{2}\right)$, $\mathrm{Pu}$ adalah beban batas $(\mathrm{kN})$, dan $\mathrm{A}$ adalah luas beban $\left(\mathrm{m}^{2}\right)$ (Hardiyatmo, 2003).

\section{METODOLOGI}

Tahap-tahap penelitian yang dilakukan dapat dilihat lebih lanjut pada Gambar 3 mengenai alur kerja penelitian yaitu sebagai berikut. Pengumpulan data dilakukan dengan menggunakan metode primer dan sekunder. Dalam penelitian ini, pengambilan data primer dilakukan dengan pengukuran tahanan jenis langsung di area ruas jalan Kawasan Industri JIIPE. Hasil dari pengumpulan data sekunder ini adalah data geologi area penelitian, parameter fisis dan mekanis tanah asli di lokasi tersebut berdasarkan uji laboratorium mekanika tanah.

Data primer hasil pengukuran meliputi nilai perbedaan potensial antara dua elektroda $\mathrm{MN}$ $(\mathrm{mV})$, nilai kuat arus yang diinjeksikan ke dalam bumi melalui elektroda $A B(m A)$, nilai spontaneous potential (sp) dan nilai resistivitas semu $\rho_{a}(\Omega m)$ hasil perhitungan alat MAE. Dilakukan proses inversi data berformat dat yang telah disusun dengan metode least square inversion untuk mendapatkan model resistivitas sebenarnya bawah permukaan.

Kemudian dilakukan interpolasi data dengan metode Inverse Distance Weighting (IDW) yang prosesnya melibatkan nilai resistivitas beserta jarak yang dimiliki terhadap zona target interpolasi yang dikehendaki. Hasil Interpolasi yang dihasilkan berupa fence diagram nilai resistivitas dengan target interpolasi kedalaman maksimum sedalam 10 meter.
Pada proses clustering, data resistivitas dikorelasikan dengan data uji lab mekanika tanah meliputi nilai kadar air sampel lempung dan data sekunder meliputi nilai N-SPT dari data Borelog. Tahap ini berguna untuk memudahkan penulis dalam menentukan batasan antar lapisan tanah material dan endapan aslinya.

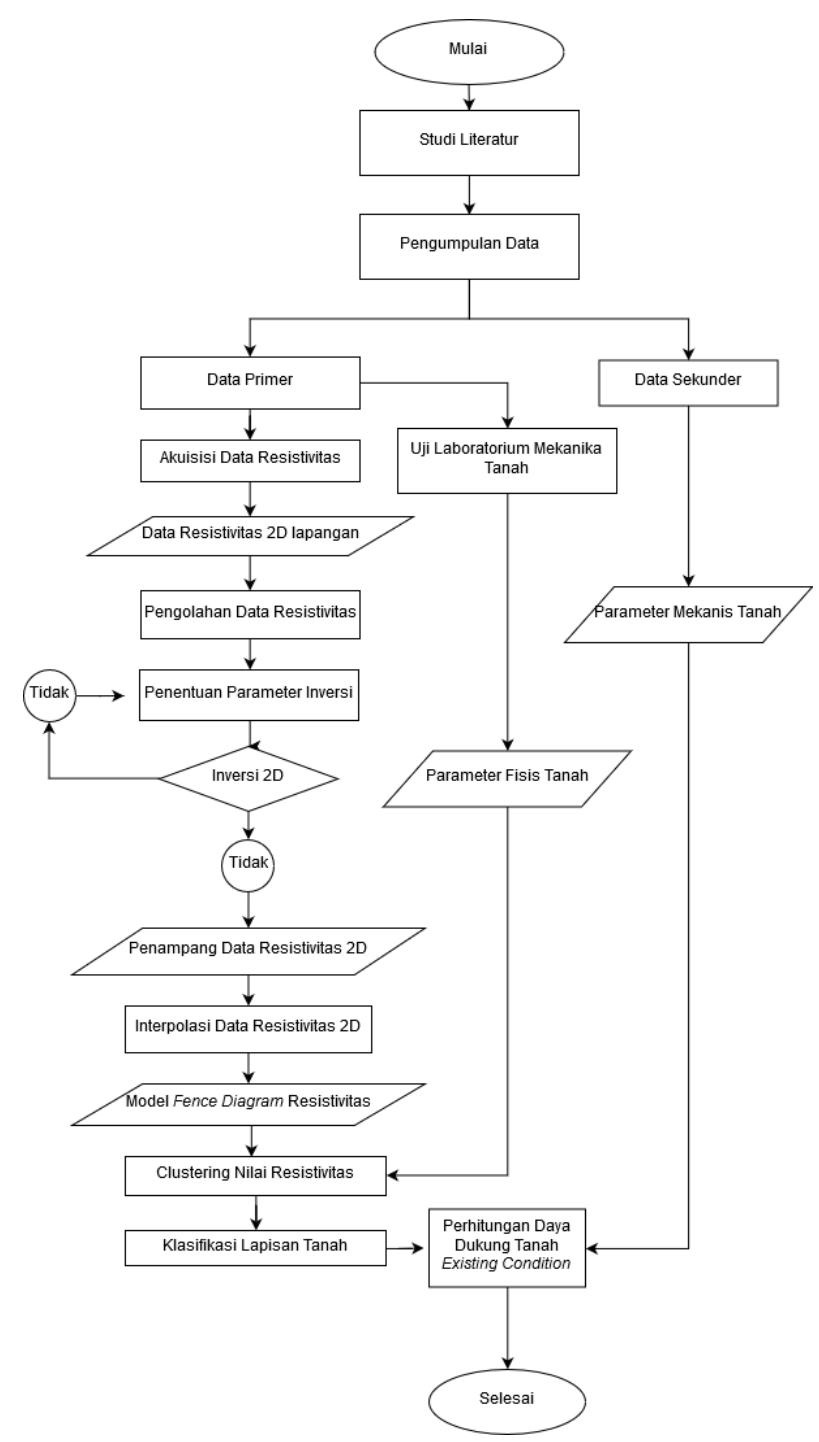

Gambar 3. Alur Kerja Penelitian

Geometri hasil clustering data resistivitas pada subbab sebelumnya merupakan acuan yang digunakan untuk menentukan ketebalan material timbunan serta acuan dalam penentuan bidang batas material timbunan dan endapan tanah asli. Untuk penentuan nilai daya dukung juga diperlukan data fisis dan mekanis tanah meliputi berat isi jenuh dan tak jenuh, koefisien permeabilitas, modulus young, poisson ratio, kohesi, sudut gesek dan sudut dilatansi. 
Penentuan nilai daya dukung tanah dilakukan melalui analisis konsolidasi dengan metode finite element. Dengan analisis konsolidasi, dapat menghitung perpindahan total yang ditentukan dari perpindahan masing masing titik nodal elemen segitiga hingga. Oleh itu untuk pengecekan beban optimum dari existing condition digunakan analisis konsolidasi dengan pendugaan beban awal sebesar $100 \mathrm{kN}$.

Dari hasil analisis konsolidasi dilakukan crossplot untuk menarik hubungan antara nilai tahapan pembebanan dengan deformasinya. Untuk mendapatkan nilai daya dukung batas (q ult) dilakukan crossplot antara nilai perpindahan total dengan faktor pengali.

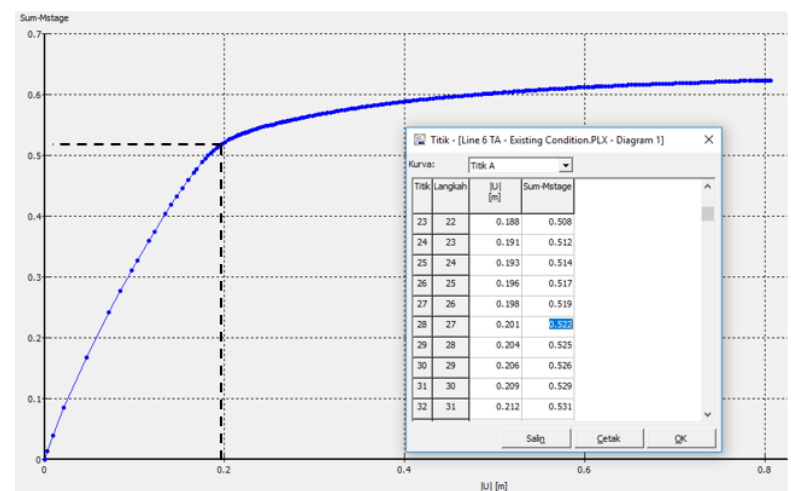

Gambar 4. Kurva Faktor Pengali Beban vs Perpindahan Total

Pembelokan arah yang terjadi pada kurva pengali beban terhadap perpindahan total merupakan indikasi bahwa formasi tanah telah mencapai batas maksimum untuk mampu mempertahankan penurunan secara efektif. Sesaat sebelum pembelokan kurva merupakan nilai beban optimum penampang yang telah didefinisikan sebelumnya, yang berarti nilai beban optimum adalah nilai daya dukung yang dimiliki penampang.

\section{HASIL DAN PEMBAHASAN}

\section{Penampang Resistivitas 2D}

Metode inversi yang dianggap paling cocok adalah metode least-square karena inversi jenis ini memiliki sensitivitas tinggi terhadap kontras resistivitas antar jenis material batuan sehingga dari penampang hasil dapat diketahui ketebalan batuan timbunan dan arah pergerakan lempung yang merupakan target pengukuran. Masing-masing penampang resistivitas yang dihasilkan memiliki rentang error mulai mulai $2 \%$ hingga $6 \%$, yang berarti validitas penampang bernilai mulai dari $94 \%$ hingga $98 \%$.

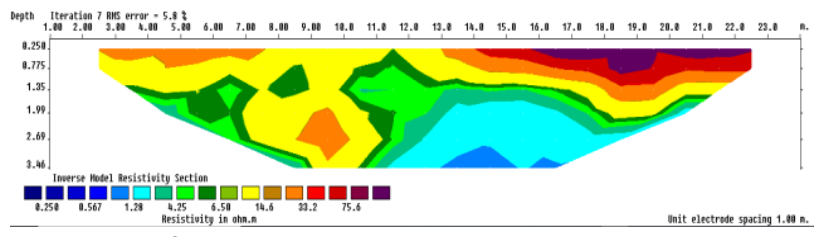

Gambar 5 Penampang Resistivitas Lintasan 4

Gambar 5 menunjukkan sampel penampang resistivitas 2D hasil pengukuran geolistrik lintasan dengan panjang lintasan 24 meter berorientasi Barat-Timur. Secara umum sebaran nilai resistivitas lintasan 4 telah merepresentasikan lintasan yang lain. Pada bagian awal lintasan hingga meter ke 12 terdapat lapisan yang diduga material timbunan dengan ketebalan $3.46 \mathrm{~m}$ dari permukaan yang diindikasikan oleh rentang resistivitas sebesar 6.50 $\Omega \mathrm{m}$ hingga $33.2 \Omega \mathrm{m}$. Sementara pada lintasan meter ke 12 hingga titik akhir lintasan diduga terdapat material timbunan baru dengan ketebalan 2.5 meter dari permukaan yang diindikasikan oleh rentang resistivitas $6.50 \Omega \mathrm{m}$ hingga $80 \Omega \mathrm{m}$. Lapisan di bawah material timbunan terdapat diduga sebagai lapisan pasir dengan indikasi nilai resistivitas $4.25 \Omega \mathrm{m}$ hingga $6.50 \Omega \mathrm{m}$ dan diikuti oleh endapan asli berupa lempung dengan indikasi nilai resistivitas $1.28 \Omega \mathrm{m}$ hingga $4.25 \Omega \mathrm{m}$.

\section{Interpolasi dan Clustering Data Resistivitas}

Gambar 6 menunjukkan fence diagrams hasil interpolasi yang sesuai dengan hasil interpretasi pada subab 4.2.1. Secara umum material timbunan pada sisi Barat memiliki rentang nilai resistivitas yang lebih kecil daripada sisi Timur yang penyebabnya diduga karena periode penimbunan yang berbeda serta faktor lingkungan yang lebih banyak mempengaruhi material timbunan di sisi Barat jalan.

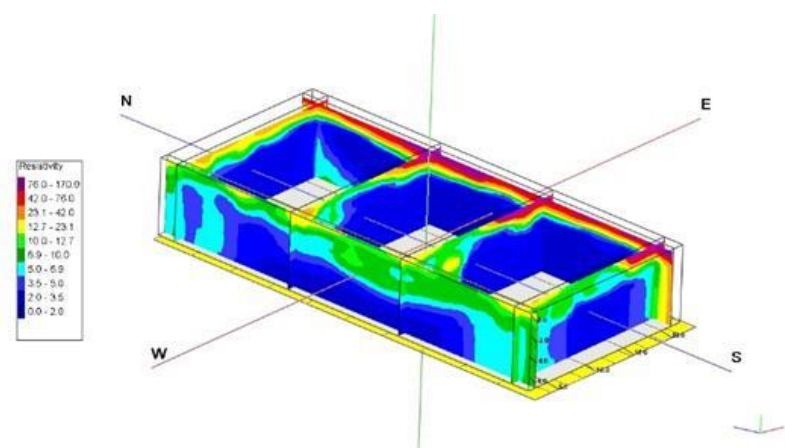

Gambar 6. Fence Diagram Tampak Sisi Barat 
Data pendukung dalam proses clustering meliputi nilai kadar air dan N-SPT borelog. Nilai kadar air hasil uji laboratorium mekanika tanah secara umum menunjukkan yang tinggi yaitu diatas 75\%. Sementara nilai N-SPT pada data borelog secara umum menunjukkan nilai yang sangat rendah yaitu di bawah 2 yang berarti material lempung memiliki tekstur very soft akibat kandungan air yang tinggi.

\section{Analisis Daya Dukung Batas Tanah}

Tabel 1. Parameter Fisis dan Mekanik Area Penelitian

\begin{tabular}{|c|c|c|c|c|}
\hline $\begin{array}{c}\text { Material } \\
\text { model }\end{array}$ & Unit & Limestone & Clay & Sand \\
\hline $\begin{array}{c}\text { Soil unit } \\
\text { weight above } \\
\text { phreatic level }\end{array}$ & $\mathbf{k N} / \mathbf{m 3}$ & 18.838 & 14.5 & 12.06 \\
\hline $\begin{array}{c}\text { Soil unit } \\
\text { weight } \\
\text { below } \\
\text { phreatic level }\end{array}$ & $\mathbf{k N / m 3}$ & 18.838 & 14.5 & 12.06 \\
\hline Permeabilitas & $\mathbf{m} /$ hari & 0.00432 & $8.64 \mathrm{E}-05$ & 8.64 \\
\hline $\begin{array}{c}\text { Koefisien } \\
\text { konsolidasi }\end{array}$ & $\mathbf{m 2} / \mathrm{hari}$ & 0.0000294 & $8.64 \mathrm{E}-05$ & 8.64 \\
\hline $\begin{array}{c}\text { Modulus } \\
\text { Young }\end{array}$ & $\mathbf{k N} / \mathbf{m 2}$ & 6965.536842 & 1723.68932 & 8139.6 \\
\hline $\begin{array}{c}\text { Modulus } \\
\text { Oedometric }\end{array}$ & $\mathbf{M p a}$ & 8.21 & 13.7464223 & $\begin{array}{c}15.261 \\
83\end{array}$ \\
\hline Poisson ratio & - & 0.24 & 0.45 & 0.25 \\
\hline Kohesi & $\mathbf{k N} / \mathbf{m} 2$ & 5.13 & 5.19 & 3.43 \\
\hline Sudut friksi & $\mathbf{0}$ & $43.84^{\circ}$ & $6^{\circ}$ & $6^{\circ} 30^{\prime}$ \\
\hline
\end{tabular}

Tabel 1 menunjukkan parameter yang digunakan dalam analisis daya dukung batas. Parameter uji lab dilakukan pada tahun 2011 untuk lapisan pasir dan lempung. Untuk parameter limestone yang dipakai adalah data uji lab Maulana (2018).

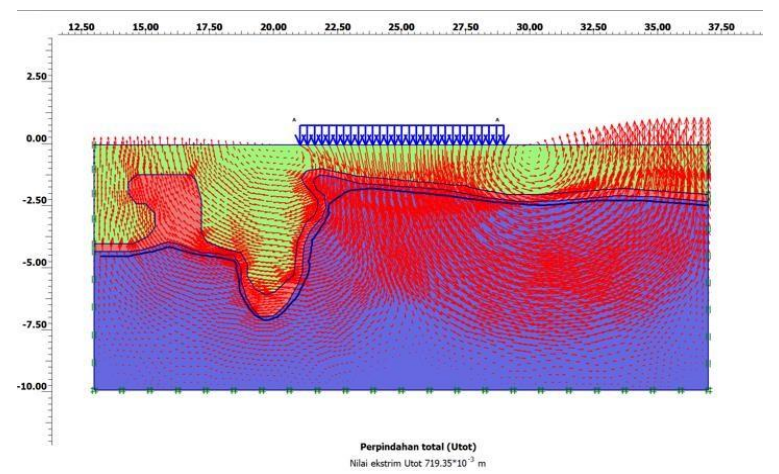

Gambar 7. Perpindahan Total Lintasan 4 dengan Beban $100 \mathrm{kN}$

Gambar 7 merupakan sampel yang diambil untuk menunjukkan perpindahan total dari analisis konsolidasi yang dilakukan pada penampang lintasan 4 dengan nilai sebesar 0.719 meter. Panah merah yang terdapat pada penampang merupakan vektor arah perpindahan tanah yang terbentuk dari penjumlahan perpindahan vertikal dan horizontal titik nodal yang merupakan tools yang digunakan untuk pendekatan dalam perhitungan metode finite element. Setiap vektor tanah yang nampak pada penampang memiliki nilai numerik masing-masing. Untuk penentuan daya dukung tanahnya, nilai dari masing masing vektor harus diubah kedalam bentuk kurva.

Masing masing kurva pada gambar 8 menunjukkan kurva nilai faktor pengali terhadap perpindahan total pada masing-masing lintasan. Sesuai dengan penjelasan sebelumnya bahwa penentuan daya dukung batas dapat diamati dari pembelokkan kurva penambahan nilai beban terhadap perpindahannya. Nilai beban sesaat sebelum pembelokan kurva disebut dengan beban optimum yang dijadikan sebagai nilai daya dukung batas (q ult). Untuk mengetahui daya dukung batas dilakukan dengan cara mengalikan nilai faktor pengali dengan penentuan beban awal perhitungan yang ditentukan sebelumnya yaitu sebesar 100 kN.

Berdasarkan perhitungan yang telah dilakukan, secara berturut-turut nilai daya dukung batas dari lintasan 3, 4, 5, dan 6 adalah 54.5 kN/m2, 58.4 $\mathrm{kN} / \mathrm{m} 2,56.2 \mathrm{kN} / \mathrm{m} 2$, dan $51.7 \mathrm{kN} / \mathrm{m} 2$. Secara umum nilai daya dukung ini dianggap kurang baik. Pernyataan tersebut dibuat karena area penelitian merupakan akses yang digunakan truk pembawa material timbunan. Berdasarkan referensi yang didapatkan berat maksimal truk beserta muatannya mencapai 10 ton atau 100 kN, sehingga perlu dilakukan upaya perbaikan untuk menanggulangi masalah tersebut. 


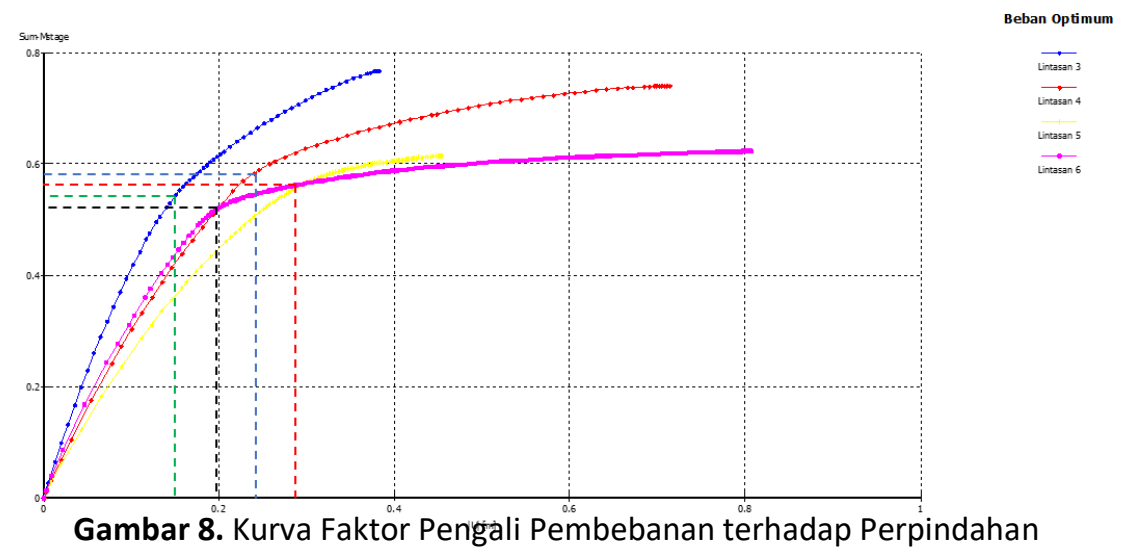

\section{PENUTUP}

\section{Simpulan}

Kesimpulan

yang didapatkan

dari

hasil penelitian yang telah dilakukan adalah:

1) Material timbunan memiliki ketebalan dari 2.5 $\mathrm{m}$ hingga $3.46 \mathrm{~m}$ dengan rentang resistivitas $6.50 \Omega \mathrm{m}$ hingga $80 \Omega \mathrm{m}$. Lapisan pasir dengan rentang resistivitas $4.25 \Omega \mathrm{m}$ hingga $6.50 \Omega \mathrm{m}$. Endapan lempung dengan rentang resistivitas $1.28 \Omega \mathrm{m}$ hingga $4.25 \Omega \mathrm{m}$.

2) Nilai daya dukung batas pada lintasan $3,4,5$, dan 6 pengukuran geolistrik berturut-turut senilai $54.5 \mathrm{kN} / \mathrm{m} 2,58.4 \mathrm{kN} / \mathrm{m} 2,56.2 \mathrm{kN} / \mathrm{m} 2$, dan $51.7 \mathrm{kN} / \mathrm{m} 2$ dianggap kurang baik..

\section{Saran}

Berdasarkan penelitian yang telah dilakukan, didapatkan saran untuk peneliti selanjutnya sebagai berikut:

1) Menambah parameter data topografi dari hasil foto udara sebagai input tambahan saat proses analisis konsolidasi untuk meningkatkan keakuratan analisis.

2) Mendapatkan data primer meliputi parameter fisis dan mekanis tanah melalui uji lab mekanika tanah supaya evaluasi lebih representatif.

\section{Ucapan Terima Kasih}

Ucapan terimakasih penulis sampaikan kepada PT. BKMS (Berkah Kawasan Manyar Sejahtera) yang telah memberikan izin kepada penulis untuk melakukan penelitian di Kawasan Industri JIIPE.

\section{DAFTAR PUSTAKA}

Arsyadi, A.Q. (2017), Identifikasi Persebaran Air Lindi Di Tpa Ngipik Kabupaten Gresik Dengan Menggunakan Metode Resistivitas $2 d$ Konfigurasi Wenner-Schlumberger, Undergraduate, Institut Teknologi Sepuluh Nopember. Diambil dari http://repository.its.ac.id/42009/.

Departemen Pekerjaan Umum (2005), Pedoman Konstruksi dan Bangunan:Stabilitas Dangkal Tanah Lunak untuk Konstruksi Timbunan Jalan.

H.C. Hardiyatmo (2002), Mekanika Tanah I, Gadjah Mada University Press, Yogyakarta.

H.C. Hardiyatmo (2003), Mekanika Tanah II, Gadjah Mada University Press, Yogyakarta.

J. Supandjono, K. Hasan, H.P. dan D. Satria, S. (1992), Peta Geologi Lembar Surabaya- Sapulu, Pusat Penelitian dan Pengembangan Geologi, Bandung.

Lida Maulida (2013), Geolistrik, FST UIN Sunan Gunung Djati, Bandung.

Pramono, G.H. (2008), AKURASI METODE IDW DAN KRIGING UNTUK INTERPOLASI SEBARAN SEDIMEN TERSUSPENSI DI MAROS, SULAWESI SELATAN, Diambil dari http://publikasiilmiah.ums.ac.id/handle/11617/ 298.

W. M. Telford, L. P. Geldart and R. E. Sheriff (1990), Applied Geophysics Second Edition. Cambridge University Press 